\title{
High prevalence of prior contact sports play and concussion among orthopedic and neurosurgical department chairs
}

\author{
Je Yeong Sone, ${ }^{1}$ S. Courtney-Kay Lamb, MD, ${ }^{2}$ Kristina Techar, BS, ${ }^{3,4}$ Vikalpa Dammavalam, BS, ${ }^{3,4}$ \\ Mohit Uppal,, Cedric Williams, MSW, ${ }^{3,4}$ Thomas Bergman, MD,, ${ }^{3,4}$ David Tupper, PhD, ${ }^{5}$ \\ Paul Ort, MD, ${ }^{6}$ and Uzma Samadani, MD, PhD ${ }^{3,4,7}$ \\ 1Department of Chemistry, New York University College of Arts and Science; ${ }^{6}$ Department of Orthopedics, VA NY Harbor \\ Healthcare, NYU School of Medicine, New York, New York; Departments of ${ }^{2}$ Rehabilitation Medicine and ${ }^{4}$ Neurosurgery, \\ University of Minnesota; ${ }^{3}$ Department of Surgery and ${ }^{5}$ Section of Neuropsychology, Hennepin County Medical Center; and \\ ${ }^{7}$ Surgery, Minneapolis VA Medical Center, Minneapolis, Minnesota
}

OBJECTIVE Increased understanding of the consequences of traumatic brain injury has heightened concerns about youth participation in contact sports. This study investigated the prevalence of high school and collegiate contact sports play and concussion history among surgical department chairs.

METHODS A cross-sectional survey was administered to 107 orthopedic and 74 neurosurgery chairs. Responses were compared to published historical population norms for contact sports (high school $27.74 \%$, collegiate $1.44 \%$ ), football (high school 10.91\%, collegiate $0.76 \%$ ), and concussion prevalence (12\%). One-proportion Z-tests, chi-square tests, and binary logistic regression were used to analyze differences.

RESULTS High school contact sports participation was 2.35 -fold higher $(65.3 \%, p<0.001)$ for orthopedic chairs and 1.73-fold higher $(47.9 \%, p=0.0018)$ for neurosurgery chairs than for their high school peers. Collegiate contact sports play was 31.0 -fold higher $(44.7 \%, p<0.001)$ for orthopedic chairs and 15.1 -fold higher $(21.7 \%, p<0.001)$ for neurosurgery chairs than for their college peers. Orthopedic chairs had a 4.30 -fold higher rate of high school football participation $(46.9 \%, p<0.001)$ while neurosurgery chairs reported a 3.05 -fold higher rate $(33.3 \%, p<0.001)$ than their high school peers. Orthopedic chairs reported a 28.1 -fold higher rate of collegiate football participation $(21.3 \%, p<0.001)$ and neurosurgery chairs reported an 8.58 -fold higher rate $(6.5 \%, p<0.001)$ compared to their college peers. The rate at which orthopedic $(42.6 \%, p<0.001)$ and neurosurgical $(42.4 \%, p<0.001)$ chairs reported having at least 1 concussion in their lifetime was significantly higher than the reported prevalence in the general population. After correction for worst possible ascertainment bias, all results except high school contact sports participation remained significant.

CONCLUSIONS The high prevalence of youth contact sports play and concussion among surgical specialty chairs affirms that individuals in careers requiring high motor and cognitive function frequently played contact sports. The association highlights the need to further examine the relationships between contact sports and potential long-term benefits as well as risks of sport-related injury.

https://thejns.org/doi/abs/10.3171/2018.1.PEDS17640

KEYWORDS traumatic brain injury; contact sports; surgeon; resilience; benefits; trauma

$\mathrm{S}$ PORT-RELATED concussion (SRC) is a common type of traumatic brain injury (TBI) that results in more than 200,000 emergency department visits annually in the United States, $65 \%$ of which involve children aged 5-18 years. ${ }^{17}$ Recognized as a major public health con- cern, ${ }^{1}$ reported SRC diagnoses have increased by $43 \%$ over the last 5 years.,39 The prevalence and clinical outcomes of concussion vary with age, ${ }^{21}$ raising concerns for higher risks and poorer outcomes in younger populations. ${ }^{12,17}$ Variable vulnerability to diffuse $\mathrm{TBI}^{8}$ may result in acute

ABBREVIATIONS $\mathrm{CI}=$ confidence interval; $\mathrm{CTE}=$ chronic traumatic encephalopathy; $\mathrm{mTBI}=$ mild $\mathrm{TBI} ; \mathrm{OR}=$ odds ratio; $\mathrm{SRC}=$ sport-related concussion; TBI = traumatic brain injury.

SUBMITTED November 14, 2017. ACCEPTED January 26, 2018.

INCLUDE WHEN CITING Published online April 27, 2018; DOI: 10.3171/2018.1.PEDS17640. 
and long-term complications in young athletes ${ }^{4,24}$ The potential complications of concussion and mild TBI (mTBI) have sparked debate about whether high-risk sports, such as football and hockey, should be banned for youths. . $^{13,18,32}$ Others have argued that the benefits of contact sports outweigh the risks ${ }^{7}$ and that efforts to protect children from sports-related TBI should be focused on safer play ${ }^{6,36}$ and more stringent return-to-play guidelines. ${ }^{28}$

Most physical benefits of exercise, such as decreased obesity,$^{19}$ increased cardiovascular health, ${ }^{20}$ and decreased risks of depression and suicidality, ${ }^{2}$ are also achievable in noncontact sports. It is unknown whether neurobiological factors associated with psychological resilience and the ability to adapt successfully in the face of stress and adversity, ${ }^{38}$ scholastic achievement, ${ }^{11,35}$ and leadership skills $^{10,15}$ are more associated with contact versus noncontact sports. However, disproportionately large numbers of individuals in highly successful careers have reported playing youth contact sports. ${ }^{25}$ Such studies have not yet been conducted on physicians. The purpose of this study is to investigate the prevalence of youth contact sports play and concussion among orthopedic and neurosurgery department chairs. We hypothesize that the rates of youth contact sports participation and concussion history among surgical department chairs are higher than in their respective peer populations.

\section{Methods}

\section{Subjects and Survey}

Email lists of all United States Accreditation Council for Graduate Medical Education-accredited orthopedic and neurosurgery department chairs were obtained via the available information from the Council of Orthopedic Residency Directors program and the American Association of Neurological Surgeons. A survey was administered via email to 107 orthopedic and 74 neurosurgery chairs (Table 1). This study was approved by the Hennepin County Medical Center Office for Human Subjects Research with a waiver of consent in accordance with Title $45 \mathrm{Sec}-$ tion 46.116 of the Code of Federal Regulations because this was a no-risk survey research.

\section{Definition of "Contact Sports"}

This study used the American Academy of Pediatrics definition of contact sports, ${ }^{33}$ which includes American football, ice hockey, rugby, wrestling, soccer, and basketball. Non-collision contact sports, including lacrosse and water polo, were categorized as "other contact sports." Sports such as field hockey and baseball were classified as noncontact sports.

\section{Population Norm Values}

Population norm values were derived for males only because only 1 respondent was female. Published data from the National Federation of State High School Associations from 1970 to 1980 were used to determine the number of male high school students who participated in American football, rugby, wrestling, soccer, and basketball. ${ }^{31}$ We used these values to derive the sum and mean of male high school students who played contact sports
TABLE 1. Survey questions administered to orthopedic and neurosurgery chairpersons

\begin{tabular}{ll}
\hline \multicolumn{1}{c}{ Question } & \multicolumn{1}{c}{ Response } \\
\hline Did you play contact sports in high school? & Yes \\
& No \\
\hline What contact sports did you play? & Free response \\
\hline What non-contact sports did you play? & Free response \\
\hline Did you play contact sports in college? & Yes \\
& No \\
\hline What contact sports did you play? & Free response \\
\hline What non-contact sports did you play? & Free response \\
\hline Do you think you ever had a concussion? & Yes, once \\
& Yes, more than once \\
& No \\
\hline Was it during school sports or another activity? & Free response \\
Please describe the event(s). & \\
\hline
\end{tabular}

between 1970 and 1980. National Collegiate Athletic Association data were similarly used to determine the sum and mean number of college students who participated in contact sports between 1981 and 1990. ${ }^{22}$ The total number of high school students enrolled between 1970 and 1980 (recorded years: 1970, 1975, 1978, 1979, 1980) and college students enrolled between 1981 and 1990 (every year) were obtained from reports by the United States Census Bureau, ${ }^{37}$ from which percentages of contact sports participation were derived. Population norms were calculated for American football but not for other contact sports because the subjects' self-reported participation rates were insufficient for statistical analysis. A concussion prevalence of $12 \%$ in developed countries, including the United States, was used as population norm. ${ }^{16}$

\section{Statistical Analysis}

One-proportion Z-tests were used to compare the frequencies of orthopedic and neurosurgery chairpersons who reported high school and college contact sports and football participation and concussion history versus the respective population norms. The $95 \%$ confidence intervals (CIs) of the Z-tests were Clopper-Pearson exact intervals. ${ }^{5,14}$ Chi-square tests were used to compare the frequencies between the orthopedic and neurosurgery groups. Binary logistic regression was used for multivariate analysis of concussion prevalence after controlling for contact sports participation and surgical specialty. Statistical significance was set at $\alpha<0.05$. Analyses were performed using IBM SPSS v.22 software.

\section{Results}

\section{Study Respondents}

Forty-nine (45.8\%) of 107 orthopedic surgery chairs and $48(64.9 \%)$ of 74 neurosurgery chairs responded to questions about high school contact sports participation. Fortyseven $(43.9 \%)$ of the orthopedic chairs and $46(62.2 \%)$ of the neurosurgery chairs provided information on their college contact sports participation. Forty-seven (43.9\%) of 
the orthopedic chairs and $45(60.8 \%)$ of the neurosurgery chairs provided information on their concussion history. Of those who responded about their concussion history, 24 (51.1\%) of the orthopedic and 19 of the (42.2\%) neurosurgery chairs specified their cause of concussion.

\section{Population Norm Values}

The mean annual number of US high school students between 1970 and 1980 was 7.64 million..$^{37}$ The mean annual number of high school students who participated in contact sports in that decade was 2,119,912. ${ }^{31}$ This yielded a population norm for high school contact sports participation of $27.74 \%$. The mean annual number of US college students between 1981 and 1990 was 5.97 million; ${ }^{37}$ $86,227^{22}$ on average participated in contact sports annually. This yielded a population norm of $1.44 \%$ for college contact sports participation. Among high school males, football participation was calculated to be $10.91 \%$ (mean $833,766^{31}$ out of 7.64 million students ${ }^{37}$ ). In college, the frequency was $0.758 \%$ (mean $45,295^{22}$ out of 5.97 million students $\left.{ }^{37}\right)$.

\section{Surgical Department Chair Participation in Contact Sports}

Thirty-two (65.3\%) of 49 orthopedic surgery chairpersons and $23(47.9 \%)$ of 48 neurosurgery chairpersons self-reported high school contact sports participation (Fig. 1A). These percentages were significantly higher for both orthopedic $(\mathrm{Z}=5.872, \mathrm{p}<0.001)$ and neurosurgery chairs $(\mathrm{Z}=3.120, \mathrm{p}=0.0018)$ compared to the population $(27.74 \%)$. The $95 \%$ CIs were $50.36 \%-78.32 \%$ and $33.27 \%-62.80 \%$, respectively. Descriptively, the rate of contact sports participation in high school for orthopedic chairs was 2.35 -fold higher and for neurosurgery chairs was 1.73 -fold higher than that of their peers. Compared to the population norm of $1.44 \%$, significantly higher prevalence of collegiate contact sports participation was reported by 21 of 47 orthopedic chairs $(44.7 \%, 95 \%$ CI $30.19 \%-59.90 \%, \mathrm{Z}=24.895, \mathrm{p}<0.001)$ and 10 of 46 neurosurgery chairs $(21.7 \%, 95 \%$ CI $10.92 \%-36.32 \%, \mathrm{Z}$ $=11.534, \mathrm{p}<0.001$ ) (Fig. 1A). Descriptively, orthopedic and neurosurgery chairs' collegiate contact sports participation rates were 31.0 -fold and 15.1-fold higher than that of their college peer population.

Twenty-three of 49 orthopedic chairs $(46.9 \%, 95 \%$ CI $32.50 \%-61.69 \%, \mathrm{Z}=8.081, \mathrm{p}<0.001)$ and 16 of 48 neurosurgery chairs $(33.3 \%$, 95\% CI $20.37 \%-48.34 \%$, $\mathrm{Z}=4.976, \mathrm{p}<0.001$ ) reported playing high school football; these rates were both significantly higher than the population norm at $10.91 \%$ (Fig. 1A). Collegiate football participation showed similar, significantly higher results for both groups (Fig. 1A). Relative to the population norm at $0.758 \%, 10$ of 47 orthopedic chairs $(21.3 \%, 95 \% \mathrm{CI}$ $10.72 \%-35.69 \%, \mathrm{Z}=16.237, \mathrm{p}<0.001)$ and 3 of 46 neurosurgery chairs $(6.5 \%, 95 \%$ CI $1.36 \%-17.87 \%, Z=4.490$, $\mathrm{p}<0.001)$ had played football in college. Descriptively, high school football participation rates were 4.30 -fold and 3.05-fold higher for orthopedic and neurosurgery chairs

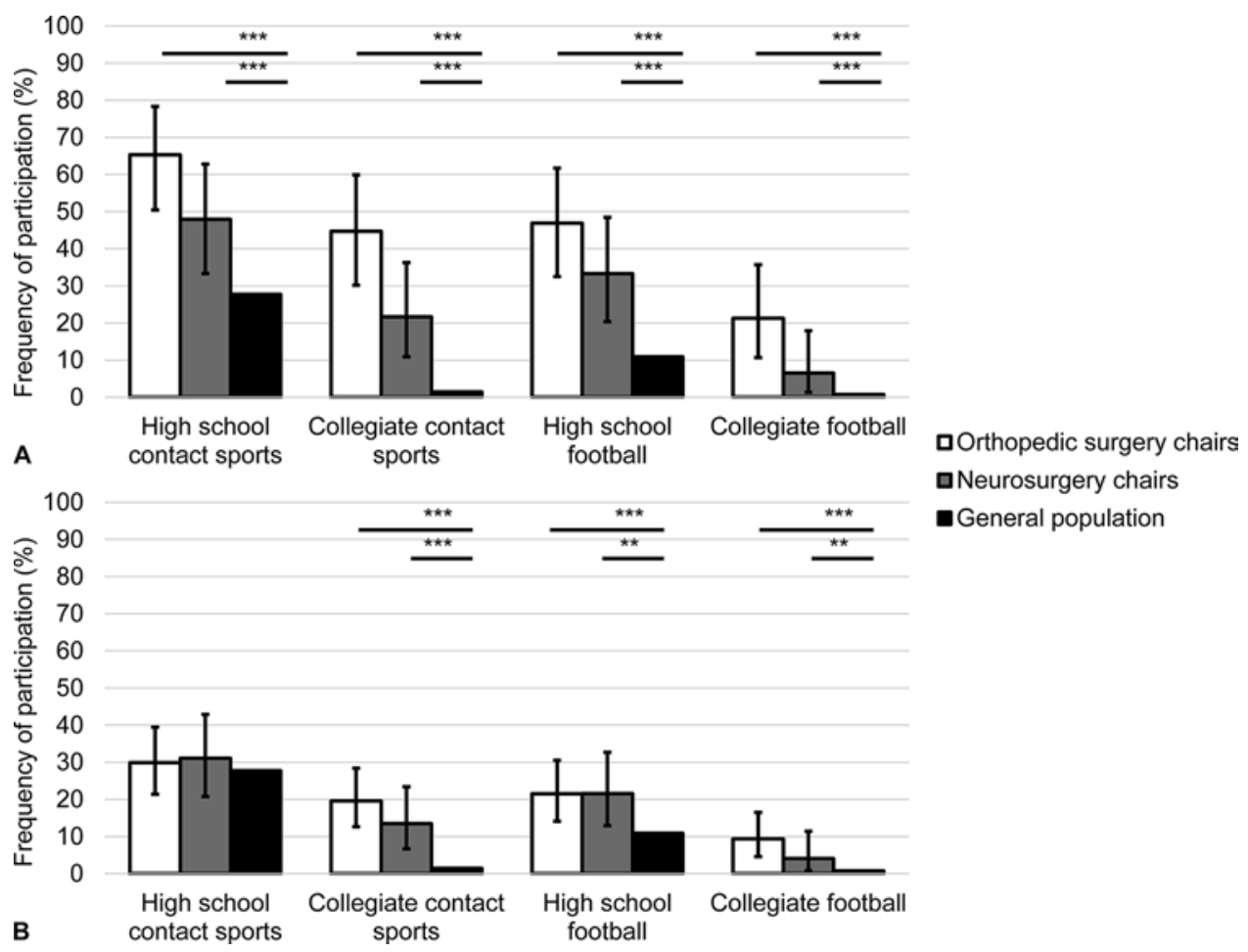

FIG. 1. A: Bar graph comparisons of orthopedic surgery chairs, neurosurgery chairs, and the general population in rates of participation in high school and collegiate contact sports (i.e., American football, ice hockey, soccer, wrestling, rugby, and basketball), and high school and collegiate football participation. B: Comparison of orthopedic surgery chairs, neurosurgery chairs, and the general population in high school and collegiate contact sports and high school and collegiate football participation rates after correcting for worst ascertainment bias. Vertical bars represent Clopper-Pearson exact $95 \%$ Cls. ${ }^{*} p<0.05 .{ }^{* *} p<0.01 .{ }^{* * *} p<0.001$. 
than for their peers, respectively, and 28.10-fold and 8.58fold higher for collegiate football.

There were no significant differences between orthopedic and neurosurgery chairs in their rates of participation in high school contact sports $\left(\chi^{2}=2.987, \mathrm{p}=0.084\right)$ and high school football $\left(\chi^{2}=1.867, \mathrm{p}=0.172\right)$. However, orthopedic chairs reported significantly higher rates of collegiate contact sports $\left(\chi^{2}=5.506, \mathrm{p}=0.019\right)$ and football participation $\left(\chi^{2}=4.209, \mathrm{p}=0.040\right)$.

Our initial data analysis was performed with the premise that survey respondents were representative of all surgeons. Since it is conceivable that only surgeons who played sports opted to answer the survey, nonrespondents were subsequently assumed to have not played contact sports, and analyses were repeated to correct for worst possible ascertainment bias. To account for both with and without this bias assumption, we repeated the analysis with the 58 orthopedic surgery and 26 neurosurgery chairs who did not respond added to the data set as having not participated in sports. With this assumption, 21/107 $(19.6 \%, 95 \%$ CI $12.56 \%-28.39 \%)$ of orthopedic and 10/74 $(13.5 \%, 95 \%$ CI $6.67 \%-23.43 \%)$ of neurosurgery chairs had participated in collegiate contact sports. Participation rates among orthopedic $(\mathrm{Z}=15.768, \mathrm{p}<0.001)$ and neurosurgery $(Z=8.708, p<0.001)$ chairs were significantly higher compared to the population norm of $1.44 \%$ (Fig. 1B). Statistical significance remained for high school and collegiate football play as well. Both orthopedic $(\mathrm{Z}=$ $3.514, p<0.001)$ and neurosurgery $(Z=2.950, p=0.003)$ chairs reported significantly higher prevalences of high school football participation relative to the population norm (10.91\%) (Fig. 1B). Twenty-three of 107 (21.5\%,95\% CI $14.14 \%-30.49 \%)$ orthopedic and 16 of $74(21.6 \%, 95 \%$ CI $12.88 \%-32.70 \%$ ) neurosurgery chairs had played high school football after ascertainment bias was assumed. Ten of $107(9.35 \%, 95 \%$ CI $4.58 \%-16.52 \%)$ orthopedic chairs $(Z=10.247, p<0.001)$ and 3 of $74(4.05 \%, 95 \%$ CI $0.84 \%-11.39 \%)$ neurosurgery chairs $(Z=3.265$, $\mathrm{p}=$ 0.001) reported collegiate football participation, both of which were significantly higher compared to the population norm of $0.758 \%$ (Fig. 1B).

Significance was lost for high school contact sports participation in comparison of both orthopedic $(29.9 \%, 32 / 107$, $\mathrm{Z}=0.499, \mathrm{p}=0.618)$ and neurosurgery $(31.1 \%, 23 / 74, \mathrm{Z}=$ $0.646, \mathrm{p}=0.519)$ groups versus the general population at $27.7 \%$ (Fig. 1B). Their 95\% CIs were $21.43 \%-39.52 \%$ and $20.84 \%-42.92 \%$, respectively. The surgical specialty type did not impact results. No significant differences were found between orthopedic and neurosurgery chairs in high school contact sports $\left(\chi^{2}=0.0285, \mathrm{p}=0.8659\right)$, college contact sports $\left(\chi^{2}=1.1516, \mathrm{p}=0.2832\right)$, high school football $\left(\chi^{2}=0.0004, p=0.9838\right)$, or collegiate football participation $\left(\chi^{2}=1.8375, \mathrm{p}=0.1752\right)$. Descriptive statistics summarizing the responses of physicians regarding participation in other contact sports (without correction of ascertainment bias) are shown in Fig. 2A and B.

\section{Prior Concussion History}

Twenty of $47(42.6 \%, 95 \%$ CI $28.30 \%-57.87 \%)$ orthopedic surgery chairs and 19 of $45(42.4 \%, 95 \%$ CI $27.64 \%-$ $57.83 \%$ ) neurosurgery chairs reported having sustained at least 1 prior concussion during their lives. Compared to the population in developed countries at $12 \%,{ }^{16}$ both orthopedic surgery $(Z=6.456, p<0.001)$ and neurosurgery chairs $(\mathrm{Z}=6.234, \mathrm{p}<0.001)$ had significantly higher prevalence of concussion (Fig. 3). Descriptively, respectively, orthopedic and neurosurgery chairs had 3.55-fold and 3.53-fold higher frequencies of positive concussion history than the general population. No significant differences were found between orthopedic and neurosurgery chairs $\left(\chi^{2}=0.001\right.$, $\mathrm{p}=0.974)$. Of the surgical department chairs who specified their cause of concussion, 70.8\% (17/24) of orthopedic surgery chairs and $63.2 \%(12 / 19)$ of neurosurgery chairs reported that their concussion was due to contact sports (Table 2). In addition, $45.8 \%$ (11/24) of orthopedic surgery chairs and $36.8 \%$ (7/19) of neurosurgery chairs reported that football was the cause of their concussion (Table 2). Neither contact sports $\left(\chi^{2}=0.285, p=0.594\right)$ nor football
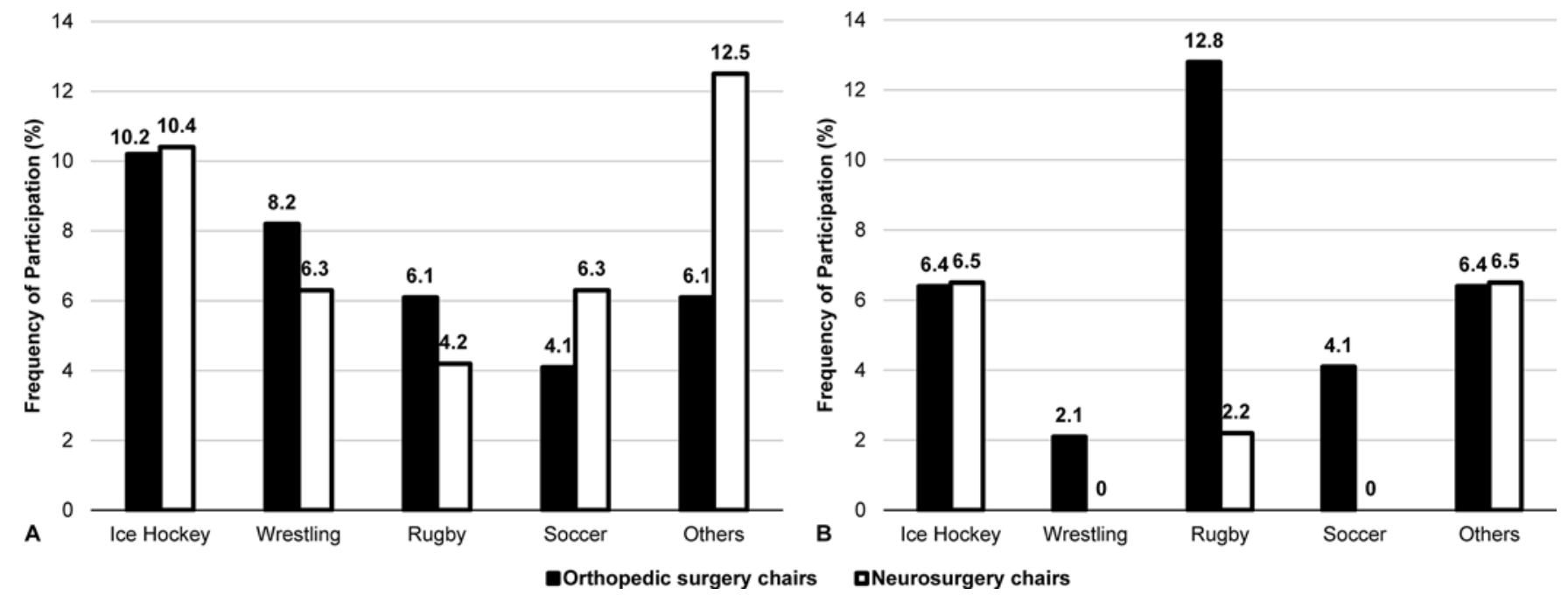

FIG. 2. Descriptive bar graph comparisons of orthopedic surgery and neurosurgery chairs with respect to rates of participation in different types of high school (A) and collegiate (B) contact sports. 

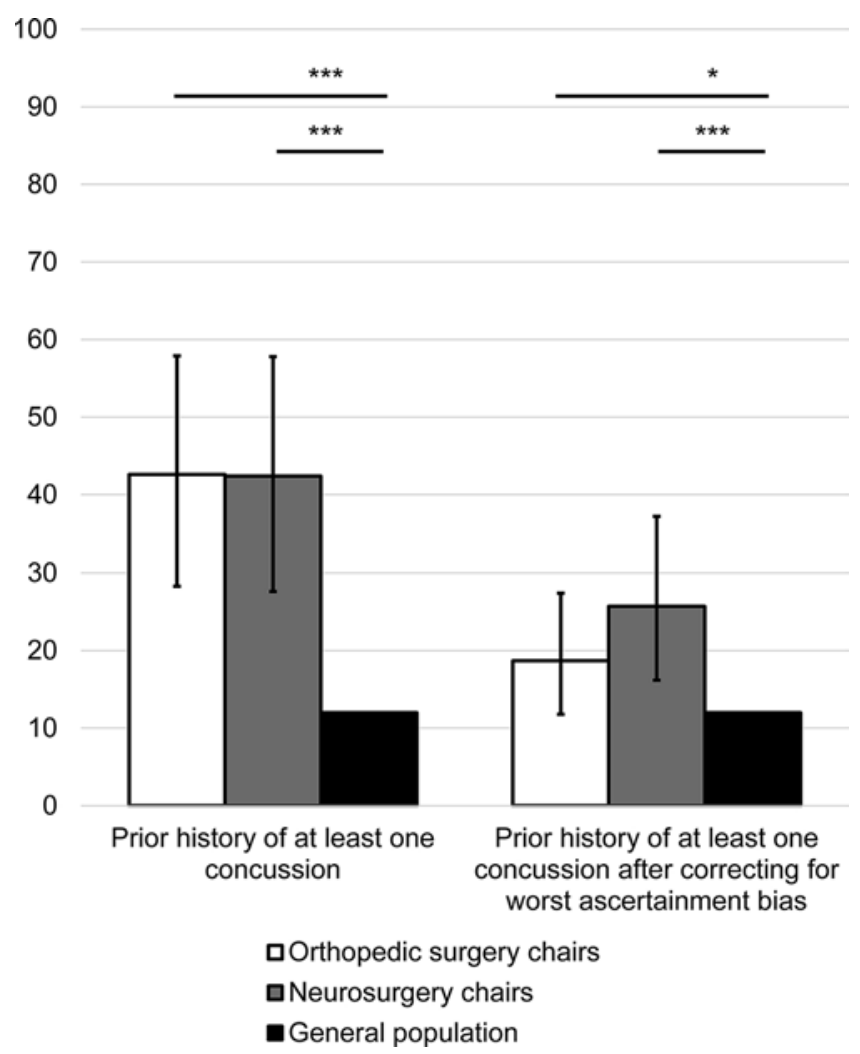

FIG. 3. Bar graph comparisons of orthopedic surgery chairs, neurosurgery chairs, and the general population in their lifetime prevalence of at least 1 prior concussion and the same comparison made after correcting for ascertainment bias. Vertical bars represent Clopper-Pearson exact $95 \%$ Cls. ${ }^{*} p<0.05 .{ }^{* *} p<0.01 .{ }^{* * *} p<0.001$.

$\left(\chi^{2}=0.352, p=0.553\right)$ as the self-reported causes of concussion showed significant differences between the frequencies in the orthopedic and neurosurgery chair groups. In these reported SRCs, football was the most common reason for both orthopedic $(64.7 \%, 11 / 17)$ and neurosurgery $(58.3 \%, 7 / 12)$ chairs, descriptively.

After controlling for surgical department type, the odds of having had at least 1 prior concussion were significantly higher for chairs who had participated in high school contact sports (odds ratio [OR] 10.621, 95\% CI 3.661-30.812, $\mathrm{p}<0.001$ ). This is further described in Table 3. Surgical specialty was not significant in the binary logistic regression model $(p=0.439)$. Other covariates of collegiate contact sports and high school and collegiate football participation were discounted because they were not statistically significant.

Nonrespondents were subsequently assumed to not have had any history of concussion, and analyses were repeated to correct for worst possible ascertainment bias. The 60 orthopedic surgery and 29 neurosurgery chairs who did not respond were added to the data set as not having had any concussion. Twenty of 107 (18.7\%, 95\% CI $11.81 \%-27.39 \%)$ orthopedic and 19 of $74(25.7 \%, 95 \%$ CI $16.24 \%-37.18 \%$ ) neurosurgery chairs had sustained at least 1 prior concussion after correction for ascertainment bias. These rates were significantly higher than the population norm of $12 \%$ for both orthopedic $(\mathrm{Z}=2.133, \mathrm{p}=$
TABLE 2. Proportion of orthopedic surgery and neurosurgery chairs who reported that their concussion was due to contact sports and football

\begin{tabular}{ccc}
\hline Description & $\begin{array}{c}\text { Orthopedic Surgery } \\
\text { Chairs }(n=24)\end{array}$ & $\begin{array}{c}\text { Neurosurgery } \\
\text { Chairs }(n=19)\end{array}$ \\
\hline $\begin{array}{c}\text { Reported having concussion } \\
\text { due to contact sports }\end{array}$ & $70.8 \%(17 / 24)$ & $63.2 \%(12 / 19)$ \\
\hline $\begin{array}{c}\text { Reported having concussion } \\
\text { due to football }\end{array}$ & $45.8 \%(11 / 24)$ & $36.8 \%(7 / 19)$ \\
\hline
\end{tabular}

$0.0329)$ and neurosurgery $(\mathrm{Z}=3.627, \mathrm{p}<0.001)$ groups (Fig. 3). There was no significant difference in concussion prevalence between orthopedic and neurosurgery chairs $\left(\chi^{2}=1.2623, p=0.2612\right)$. After controlling for surgical specialty, we found that chairs who played high school contact sports had 35.51 times the odds of having sustained at least 1 concussion in their lives $(p<0.001$; 95\% CI of OR 12.914-97.648) (Table 4). Surgery department type was not significant in the binary logistic regression model $(\mathrm{p}=0.439)$. Participation in collegiate contact sports and high school and college football were removed because they were not significant in the model.

\section{Discussion}

\section{Summary of Major Findings}

Orthopedic surgery and neurosurgery chairs surveyed in this study had significantly higher rates of participation in high school and collegiate contact sports, including American football, relative to the general population. Both types of surgeons had significantly higher frequencies of at least 1 prior concussion than the general population. Even after correction for possible ascertainment bias, all results maintained significance except high school contact sports participation. The majority of concussions were reported by both neurosurgery and orthopedic surgery chairs to be due to contact sports, while football was the most commonly indicated reason for the SRCs. High school contact sports participation was associated with significantly higher odds of having had at least 1 prior concussion after controlling for surgical specialty. It is important to note that our findings suggest only that contact sports participation does not necessarily preclude an individual from achieving a career of high motor and cognitive functions and demands. In other words, contact sports play may not necessarily be a risk factor against careers associated with socioeconomic success and prestige and motor and cognitive aptitude. However, we must emphasize that we cannot dismiss potential burdens of injury, subsequent head impacts, secondary neurological sequelae, and the extent of safety and risks associated with contact sports.

\section{Limitations of the Study}

This study's limitations include reliance on self-report, lower response rate by orthopedic surgery chairs, and moderate response rates for both groups. Self-report may result in recall bias of concussion and contact sports participation history. Lower response rates may be attributable to the possibility that subjects who are interested 
TABLE 3. Binary logistic regression of the association between high school contact sports play and prevalence of prior concussion history after controlling for surgical department type

\begin{tabular}{|c|c|c|c|c|c|c|}
\hline & B & $\mathrm{OR}^{*}$ & $95 \% \mathrm{Cl}$ of $\mathrm{OR}$ & p Value & Cox \& Snell R² & Nagelkerke $\mathrm{R}^{2}$ \\
\hline High school contact sports participation & 2.363 & 10.621 & $3.661-30.812$ & $<0.001$ & \multirow{3}{*}{0.229} & \multirow{3}{*}{0.308} \\
\hline Surgical department type & 0.386 & 1.470 & $0.554-3.903$ & 0.439 & & \\
\hline Constant & -1.969 & 0.140 & NA & $<0.001$ & & \\
\hline
\end{tabular}

NA = not applicable.

Concussion history was defined as at least 1 prior concussion.

* $\mathrm{e}^{\mathrm{B}}$ or odds ratio (OR).

in neurotrauma and contact sports may be more likely to respond to the survey. The response rates and sample sizes represent approximately or more than half of the entire aforementioned populations of surgical department chairs and thus are still sufficient for analysis and generalizability. The physicians in our study had a higher reported prevalence of concussion than the general population, but this may be at least partially attributable to better awareness of concussion among physicians than in laypeople. It is also possible that subjects who have had concussions may not have wanted to disclose such information, but this bias may be offset because the reported concussion rates are significantly higher than the general population. Accounting for this bias would increase the rate differences between surgical department chairs and the population. Other limitations include lack of standardized threshold for the extent of sports participation and standardized definition for concussion. Our findings may be limited to the male sex because only 1 respondent was female. Our reliance on the use of multiple reports to derive the population norms of high school and collegiate contact sports limits the accuracy of statistical analyses. An additional caveat is that our findings are applicable only to former high school and college students who played in the era of our study population and not necessarily in the current era, where youth may specialize in a single sport at a younger age.

\section{The Complex Benefits and Risks of Contact Sports Play}

The high prevalence of contact sports play among surgical department chairs raises questions regarding whether potential long-term benefits of contact sports may conceivably balance against risks of sport-related injury. Less understood is whether noncontact sports may have similar benefit with less risk than contact sports.

Benefits of sports are widely recognized: they foster leadership skills and psychological and physical resilience in youth, ${ }^{15}$ with potential long-term career benefits. ${ }^{25}$ World War II veterans who had played high school sports were found to have greater likelihood of "upper management"level careers than those who participated in nonsporting high school extracurricular activities. ${ }^{25}$ These effects were shown to persist over 55 years. ${ }^{25}$ Those who played high school sports also scored higher in a leadership measure based on self-perception of their character. ${ }^{10}$

The risks of sport-related injury are less understood. Some have argued that TBI and cumulative subconcussive hits are progressively damaging, consequently leading to neurodegenerative diseases such as chronic traumatic encephalopathy (CTE) ${ }^{30}$ However, 2 prospective cohort studies showed that high school football players from 19461956 and 1956-1970 did not have significantly increased risk for developing neurodegenerative diseases later in life. ${ }^{23,34}$ High school football players of years 1956-1970 had significantly higher risk for medically documented TBI compared to their peers who played basketball, swimming, or wrestling, but not football. ${ }^{23}$ A recent study of Wisconsin high school football players from 1957 showed no increased risk for cognitive impairment or dementia even to the age of $72 .{ }^{9}$

In addition, a pooled prospective cohort study showed that self-reported history of TBI with loss of consciousness was associated with pathological findings and risk for some types of neurodegeneration (e.g., Lewy body formations and Parkinson's disease), but not dementia, Alzheimer's disease, and neurofibrillary tangles.? Study of the Queen's Square Brain Bank revealed that the incidence of postmortem CTE diagnosis does not differ significantly between people who died in their 70s and 80s with clinical neurodegenerative diseases (11.8\%) versus neurologically healthy (12.8\%). ${ }^{26}$ The uncertainty regarding the link between sports play and TBI and CTE led to an NIH-funded consortium to define its updated diagnostic criteria, ${ }^{29,30}$ and examining the pathologic nature and developing the diagnostics of CTE are under evolving progress. The literature and our findings suggest that the relationship between contact sports play and later-life outcomes is neither

TABLE 4. Binary logistic regression of the association between high school contact sports play and prevalence of prior concussion history after controlling for surgical department type

\begin{tabular}{|c|c|c|c|c|c|c|}
\hline & $\mathrm{B}$ & OR & $95 \% \mathrm{Cl}$ of $\mathrm{OR}$ & $p$ Value & Cox \& Snell $\mathrm{R}^{2}$ & Nagelkerke $\mathrm{R}^{2}$ \\
\hline High school contact sports participation & 3.570 & 35.511 & $12.914-97.648$ & $<0.001$ & \multirow{3}{*}{0.334} & \multirow{3}{*}{0.512} \\
\hline Surgical department type & 0.623 & 1.864 & $0.716-4.854$ & 0.202 & & \\
\hline Constant & -3.268 & 0.038 & NA & $<0.001$ & & \\
\hline
\end{tabular}

This model is corrected for worst possible ascertainment bias. Prior concussion history was defined as at least 1 prior concussion. 
a straightforward association between risky activities predisposed to neurotrauma and unfavorable outcome nor a direct association between contact sports and success in life. It is also likely that inherent personal qualities such as competitiveness, extroversion, and egocentrism have mediating effects. Our findings suggest that the net risks and benefits of contact sports participation require further study in order to understand fully the consequences of allowing youths to engage in contact sports or discourage them from participation.

\section{Conclusions}

In summary, youth contact sports participation and concussion are more frequent in orthopedic and neurosurgery chairs than in the general population. Potential shortand long-term benefits of team contact sports may provide a complex balance with the risks of sports-related injuries. Better understanding of the risks and benefits in contact versus noncontact sports play is required prior to imposition of limitations on play.

\section{References}

1. Arbogast KB, Curry AE, Pfeiffer MR, Zonfrillo MR, Haarbauer-Krupa J, Breiding MJ, et al: Point of health care entry for youth with concussion within a large pediatric care network. JAMA Pediatr 170:e160294, 2016

2. Babiss LA, Gangwisch JE: Sports participation as a protective factor against depression and suicidal ideation in adolescents as mediated by self-esteem and social support. J Dev Behav Pediatr 30:376-384, 2009

3. Blue Cross Blue Shield Association: The steep rise in concussion diagnoses in the United States. Blue Cross Blue Shield. September 27, 2016. (https://www.bcbs.com/the-health-ofamerica/reports/steep-rise-concussion-diagnoses-us) [Accessed February 22, 2018]

4. Buzzini SR, Guskiewicz KM: Sport-related concussion in the young athlete. Curr Opin Pediatr 18:376-382, 2006

5. Clopper CJ, Pearson ES: The use of confidence or fiducial limits illustrated in the case of the binomial. Biometrika 26:404-413, 1934

6. Council on Sports Medicine and Fitness: Tackling in youth football. Pediatrics 136:e1419-e1430, 2015

7. Crane PK, Gibbons LE, Dams-O'Connor K, Trittschuh E, Leverenz JB, Keene CD, et al: Association of traumatic brain injury with late-life neurodegenerative conditions and neuropathologic findings. JAMA Neurol 73:1062-1069, 2016

8. Daneshvar DH, Riley DO, Nowinski CJ, McKee AC, Stern RA, Cantu RC: Long-term consequences: effects on normal development profile after concussion. Phys Med Rehabil Clin N Am 22:683-700, ix, 2011

9. Deshpande SK, Hasegawa RB, Rabinowitz AR, Whyte J, Roan CL, Tabatabaei A, et al: Association of playing high school football with cognition and mental health later in life. JAMA Neurol 74:909-918, 2017

10. Dobosz RP, Beaty LA: The relationship between athletic participation and high school students' leadership ability. Adolescence 34:215-220, 1999

11. Esteban-Cornejo I, Tejero-González CM, Martinez-Gomez D, del-Campo J, González-Galo A, Padilla-Moledo C, et al: Independent and combined influence of the components of physical fitness on academic performance in youth. J Pediatr 165:306-312, 312.e1-312.e2, 2014

12. Field M, Collins MW, Lovell MR, Maroon J: Does age play a role in recovery from sports-related concussion? A comparison of high school and collegiate athletes. J Pediatr 142:546-553, 2003
13. Fishman M, Taranto E, Perlman M, Quinlan K, Benjamin HJ, Ross LF: Attitudes and counseling practices of pediatricians regarding youth sports participation and concussion risks. J Pediatr 184:19-25, 2017

14. Fleiss JL, Levin B, Paik MC: Statistical Methods for Rates and Proportions, ed 3. Hoboken, NJ: Wiley, 2003

15. Fraser-Thomas JL, Côté J, Deakin J: Youth sport programs: an avenue to foster positive youth development. Phys Educ Sport Pedagogy 10:19-40, 2005

16. Frost RB, Farrer TJ, Primosch M, Hedges DW: Prevalence of traumatic brain injury in the general adult population: a meta-analysis. Neuroepidemiology 40:154-159, 2013

17. Gilchrist J, Thomas KE, Wald M, Langlois J: Nonfatal traumatic brain injuries from sports and recreation activitiesUnited States, 2001-2005. MMWR Morb Mortal Wkly Rep 56:733-737, 2007

18. Glatter R: The reasons not to ban contact sports for children: an answer to 'Concussion.' Forbes. December 23, 2015. (https://www.forbes.com/sites/robertglatter/2015/12/23/thereasons-not-to-ban-contact-sports-in-children-an-answer-tothe-concussion-movie) [Accessed February 22, 2018]

19. Hatfield DP, Chomitz VR, Chui KKH, Sacheck JM, Brown AA, Economos CD: Impact of a community-based physical activity program on fitness and adiposity among overweight and obese children. Health Promot Pract 18:75-83, 2017

20. Hebert JJ, Klakk H, Møller NC, Grøntved A, Andersen LB, Wedderkopp N: The prospective association of organized sports participation with cardiovascular disease risk in children (the CHAMPS Study-DK). Mayo Clin Proc 92:57-65, 2017

21. Hildenbrand KJ, Vasavada AN: Collegiate and high school athlete neck strength in neutral and rotated postures. J Strength Cond Res 27:3173-3182, 2013

22. Irick E: Student-Athlete Participation 1981-82-201415. NCAA Sports Sponsorship and Participation Rates Report. Indianapolis: National Collegiate Athletic Association, 2015 (https://www.ncaa.org/sites/default/files/ Participation\%20Rates\%20Final.pdf) [Accessed February 22, 2018]

23. Janssen PH, Mandrekar J, Mielke MM, Ahlskog JE, Boeve $\mathrm{BF}$, Josephs K, et al: High school football and late-life risk of neurodegenerative syndromes, 1956-1970. Mayo Clin Proc 92:66-71, 2017

24. Keightley ML, Sinopoli KJ, Davis KD, Mikulis DJ, Wennberg $\mathrm{R}$, Tartaglia MC, et al: Is there evidence for neurodegenerative change following traumatic brain injury in children and youth? A scoping review. Front Hum Neurosci 8:139, 2014

25. Kniffin KM, Wansink B, Shimizu M: Sports at work: anticipated and persistent correlates of participation in high school athletics. J Leadersh Organ Stud 22:217-230, 2015

26. Ling H, Holton JL, Shaw K, Davey K, Lashley T, Revesz T: Histological evidence of chronic traumatic encephalopathy in a large series of neurodegenerative diseases. Acta Neuropathol 130:891-893, 2015

27. Mannix R, Meehan WP III, Pascual-Leone A: Sports-related concussions-media, science and policy. Nat Rev Neurol 12:486-490, 2016

28. May KH, Marshall DL, Burns TG, Popoli DM, Polikandriotis JA: Pediatric sports specific return to play guidelines following concussion. Int J Sports Phys Ther 9:242-255, 2014

29. McKee AC, Cairns NJ, Dickson DW, Folkerth RD, Keene CD, Litvan I, et al: The first NINDS/NIBIB consensus meeting to define neuropathological criteria for the diagnosis of chronic traumatic encephalopathy. Acta Neuropathol 131:75-86, 2016

30. McKee AC, Stern RA, Nowinski CJ, Stein TD, Alvarez VE, Daneshvar DH, et al: The spectrum of disease in chronic traumatic encephalopathy. Brain 136:43-64, 2013

31. National Federation of State High School Associations: 
1969-2014 high school athletics participation survey results. NFHS.org. (http://www.nfhs.org/ParticipationStatics/PDF/ Participation\%20Survey\%20History\%20Book.pdf) [Accessed February 22, 2018]

32. Omalu B: Don't let kids play football. New York Times. December 7, 2015; A23. (https://www.nytimes.com/2015/12/07/ opinion/dont-let-kids-play-football.html) [Accessed February 22, 2018]

33. Rice SG: Medical conditions affecting sports participation. Pediatrics 121:841-848, 2008

34. Savica R, Parisi JE, Wold LE, Josephs KA, Ahlskog JE: High school football and risk of neurodegeneration: a communitybased study. Mayo Clin Proc 87:335-340, 2012

35. Stephens LJ, Schaben LA: The effect of interscholastic sports participation on academic achievement of middle level school students. NASSP Bull 86:34-41, 2002

36. Tucker R, Raftery M, Verhagen E: Injury risk and a tackle ban in youth Rugby Union: reviewing the evidence and searching for targeted, effective interventions. A critical review. Br J Sports Med 50:921-925, 2016

37. U.S. Census Bureau: Statistical Abstract of the United States: 1999, ed 119. Washington, DC: U.S. Census Bureau, 1999 (https://www.census.gov/library/publications/1999/ compendia/statab/119ed.html) [Accessed February 22, 2018]

38. Wu G, Feder A, Cohen H, Kim JJ, Calderon S, Charney DS, et al: Understanding resilience. Front Behav Neurosci 7:10, 2013

39. Zhang AL, Sing DC, Rugg CM, Feeley BT, Senter C: The rise of concussions in the adolescent population. Orthop J Sports Med 4:2325967116662458, 2016

\section{Disclosures}

Uzma Samadani is a consultant to Abbott Laboratories, Medtronic Public Limited Company, Integra, and the National Football
League; has grant funding from Integra and Abbott and equity in Oculogica, Inc. She has intellectual properties related to concussion and dementia diagnosis and brain injury treatment held by NYU School of Medicine, VA NY Harbor Healthcare, and Hennepin County Medical Center. She has had honoraria from Wisconsin, Minnesota, and Texas High School Coaches Associations, USA Football, continuing legal education conferences, National Neurotrauma Symposium, and the North America Brain Injury Symposium. David Tupper has received royalties for published books from Oxford University Press and Guilford Publishers, travel expenses and honorarium from the American Academy of Clinical Neuropsychology, honorarium from Psychiatric Annals, and institution grant funding for the Brain in Kidney Disease (BRINK) study.

\section{Author Contributions}

Conception and design: Samadani, Sone, Ort. Acquisition of data: Sone, Ort. Analysis and interpretation of data: Samadani, Sone, Lamb. Drafting the article: all authors. Critically revising the article: all authors. Reviewed submitted version of manuscript: all authors. Approved the final version of the manuscript on behalf of all authors: Samadani. Statistical analysis: Sone. Study supervision: Samadani, Sone.

\section{Supplemental Information \\ Previous Presentations}

Portions of this work were presented in abstract form at the Annual Meeting of the Congress of Neurological Surgeons in Boston, Massachusetts, on October 7-11, 2017, and as part of a larger oral presentation to USA Football in Orlando, Florida, in January 2017.

\section{Correspondence}

Uzma Samadani: Hennepin County Medical Center, University of Minnesota, Minneapolis, MN. uzma@samadani.com. 